\title{
ПСИХОФИЗИОЛОГИЧЕСКИЕ ОСНОВЫ ЭМПАТИИ ${ }^{1}$
}

Исследование выполнено в рамках НИР 0138-2021-0002 и при финансовой поддержке ФГБОУ ВО МГППУ

Гаврилов В.В. (Институт психологии РАН, Московский государственный психолого-педагогический университет, Москва, Россия) nvvgav@mail.ru

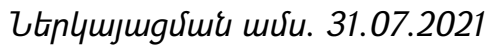

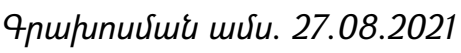

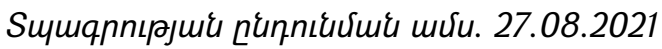

\begin{abstract}
Способность сопереживать является одной из важнейших в отношениях между индивидами: «она заставляет» их изменять свое поведение, иногда в ущерб себе, приводит к сплочению группы, и т. п., что делает изучение эмпатии важным и актуальным. Понимание эмпатии как сопереживания является не единственным: выделяют разные виды эмпатии, при этом истинной эпатией обычно наделяются только люди, а представления об организации активности мозга и психофизиологических основах эмпатии крайне малочисленны. В последнее время проявления эмпатии стали связывать с функционированием систем «зеркальных нейронов», а сам феномен эмпатии стал рассматриваться на двух уровнях: врожденном, связанном с наличием «зеркальных систем», и приобретенном, связанном С «когнитивной переработкой информации». Неопределенность в определении эмпатии, методические трудности и ограничения исследований эмпатии у людей, с одной стороны, и представления о структуре индивидуального опыта и организации активности мозга, развиваемые в системно-эволюционном подходе [2, 3], с другой, позволяют нам предположить, что психофизиологические основы эмпатии могут быть поняты в результате исследования организации активности мозга при реализации «эмпатического» поведения. Сообщаются результаты исследования эмпатии и организации активности мозга у крыс в модели инструментального пищедобывательного поведения.
\end{abstract}

Ключевые слова: эмпатия, альтруизм, крысы, инструментальное поведение.

DOI: https://doi.org/10.46991/SBMP/2021.4.2.165

1 Работа выполнена при участии Е.С.Ештокиной. 
То, что крысы испытывают эмпатию, настолько распространенное мнение, что даже не обсуждается и выносится в предисловие книг. В частности, М.Бекофро и Дж.Пирс [4] начиная свою книгу с перечисления примеров альтруистического поведения, которое они рассматривают как моральное поведение, как проявление эмпатии, в качестве примера приводят поведение крыс («Крыса в клетке отказывается нажимать на рычаг для получения пищи, если видит, что другая крыса при этом получает разряд тока» (с.іx)). Об эторм же пищет Симонов [1] и de Waal [9], ссылаясь на более ранние работы Church [5] и др.. Риззолатти с коллегами [8] рассматривают эмпатию, как функцию высшего порядка наряду с такими, как понимание действий, намерений и эмоций, а проявления эмпатии связывают с функционированием систем «зеркальных нейронов». Эрнандес-Лаллемент с коллегами [6] показали, что крысы, как самки, так и самцы, избегают действий, которые наносят вред как знакомым, так и незнакомым конспецификам. Хотя собственный опыт (получение болевого раздражения в сходных условиях) усиливает этот эффект, однако, он уменьшается с ростом «стоимости» своих затрат для оказания помощи другим.

Было найдено, что проявление эмпатии связано с активацией миндалины, островка, поля 24 передней цингулярной коры, разных областей префронтальной коры. Вместе с тем, исследования нейрофизиологических основ совместного поведения сравнительно малочисленны и недостаточно ясны [7]. Конечно, всегда остается вопрос насколько результаты исследований на животных можно экстраполировать на человека, тем не менее, мы считаем, что в исследовании на животных, реализующих одно и тоже циклическое целенаправленное инструментальное поведение, можно выявить нейрональные основы разных аспектов совместного поведения.

Методологической основой наших исследований является системноэволюционный подход к изучению мозга, поведения и психики [2, 3], согласно которому особенности поведения определяются структурой индивидуального опыта, сформированного в фило- и онтогенезе. Ранее в наших исследованиях было показано, что по системной поведенческой специализации нейронов можно судить об имеющихся у субъекта поведения элементах опыта, а по колебаниям суммарной электрической активности судить о динамике отношений между этими элементами.

Цель исследования: выяснить системную организацию индивидуального опыта при эмпатии, ее психофизиологические основы. Задачей настоящей работы было исследование одного и того же инструментального пищедобывательного поведения у крыс в отсутствии и в присутствии конспецифика, который получал разряд электрического тока всякий раз, когда другая крыса для получения порции пищи нажимала на педаль ближе 
расположенную к кормушке, тогда как она могла также получить пищу, нажимая на педаль, расположенную в два раза дальше, при этом не нанося ущерб конспецифику.

Методика. Экспериментальный дизайн. Исследование проводилось в экспериментальной клетке кубической формы с ребром 60 см. После научения крыс нажимать на педали для получения пищи (подробности - ниже), в клетку помещалась Г-образная прозрачная перегородка, при помощи которой разделялись крыса-жертва, мягко фиксированная в гамаке, от тестируемой крысы, реализующей инструментальное поведение (Рис.1, Рис.2, III). В углах клетки располагались кормушка и две педали, нажатие на которые приводило к автоматической подаче пищи в кормушку. По отношению к кормушке педали были на разном расстоянии: 40 см - ближняя педаль (БП) и 70 см - дальняя педаль (ДП).

Участники исследования. В экспериментах участвовали 8 взрослых самцов крыс Long Evans (весом от 300 до 370 г), которые содержались в домашних клетках парами. Жертвами были 5 самок 5-и месячного возраста из одной домашней клетки, а также тестируемые самцы из одной пары поочередно.

Хирургическое вживление ЭЭГ-электродов. Перед научением крысам под наркозом (раствор золетила и рометара внутримышечно) вживляли эпидурально хлорсеребряные электроды над моторной, лимбической и зрительной областями коры мозга с референтом над лобными пазухами. Импеданс электродов - около 30 кОм. После недельного восстановления переходили к научению (стадия I) (Рис.1).

Стадии научения. Крысы подвергались частичной пищевой депривации при ежедневном контроле веса и состояния животного. Обучение проводили ежедневно, длительность сессии - 30 минут. Крысы помещались в клетку и самостоятельно (без помощи экспериментатора) должны были научиться нажимать на педаль для получения порции пищи (кубик сыра размером около 1 мм3). Переходом к следующему этапу обучения/исследования было достижение критерия научения - регулярных побежек от кормушки к педали и обратно. Когда крыса научалась нажимать на ближнюю педаль (БП), педаль становилась неэффективной и крысы начинала учиться нажимать на дальнюю педаль (ДП) (стадия II). После этого обе педали становились эфффективными и крысам предоставлялась возможность для получения пищи использовать обе педали. До тестирования (стадия III) выясняли, какую педаль предпочитают крысы при свободном выборе. 

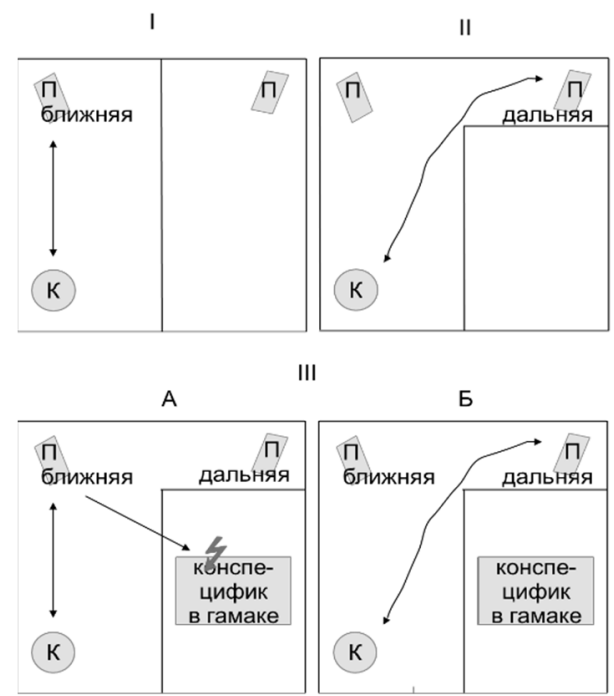

Рисунок 1. Стадии исследования: научение (I и II) и тест наличия эмпатии (III). Описание в тексте. П - педаль, $K$ - кормушка. Линиями и стрелками показаны перемещения тестируемых крыс и эфрфекты нажатия на ближнюю педаль. $A$ - поведение с ближней педалью, Б - с дальней.

Дефинитивное поведение. В исследуемом дефинитивном поведении научившиеся крысы совершали циклическое пищедобывательное поведение многократные побежки от педали к кормушке и обратно. Они могли использовать как БП, так и ДП, однако нажатие на БП приводило не только к подаче пищи, но и к электрокожному раздражению задних лап крыс-жертв в течение всего времени нажатия на педаль. Ток подбирали индивидуально для каждой крысы в начале сессии: увеличивали латером от нуля до начала вокализации у крысы-жертвы.

Регистрация поведения. Проводилась видеозапись поведения, а также фотоэлектрическая регистрация отметок нажатия на педаль и опускания головы в кормушку, которая использовалась для подсчета числа однотипных актов поведения и синхронизации актов поведения с суммарной электрической активностью мозга и ультразвуковой вокализацией крыс.

Регистрация вокализации. Для регистрации вокализации крыс, в том числе ультразвуковой, на потолке над каждой половиной экспериментальной клетки были установлены сконструированные УЗ-микрофоны (Д. Малахов), по характеристикам сходные с микрофонами Sonotrack (Metris B.V., the Netherlands). Результаты этой части работы здесь не представлены.

Результаты. Перед тестированием (стадия III) было установлено, что все крысы, участвовавшие в нашем исследовании, предпочитали БП. Все животные нажимали на ДП для получения пищи менее, чем в 10\% случаев от 
всех нажатий в экспериментальной сессии. Каждый из участвующих в исследовании самцов участвовал в 7-8 тестах на эмпатию (30-минутных сессиях описанного выше инструментального поведения). Каждый из них «работал» с каждой из пяти самок, а также со своим партнером, с которым находился в домашней клетке. При этом в одной сессии крыса нажимала на педали, а другая была жертвой, в другой - наоборот.

Ни у одной из тестируемых на проявление эмпатии крыс, ни в одной из 63 сессий не было увеличения числа нажатий на ДП: как и перед тестированием, все крысы предпочитали БП (более $90 \%$ от всех нажатий на обе педали), хотя они на протяжении всей сессии и нажимали на ДП (см. табл.1). Следует также отметить, что ни одна из крыс не отказалась от поведения, несмотря на то, что крыса-жертва издавала крики всякий раз, когда тестируемая крыса нажимала на БП, а зачастую еще до приближения этой крысы к БП.

Таблица 1.

Сравнение чисел нажатий на БП и ДП при тестировании на эмпатию в парах, содержащихся совместно самцов.

\begin{tabular}{|c|c|c|c|c|c|}
\hline $\begin{array}{l}\text { имена } \\
\text { крыс }\end{array}$ & $\begin{array}{c}\text { число нажатий } \\
\text { на БП и ДП }\end{array}$ & $\begin{array}{c}\text { число нажатий } \\
\text { на ДП }\end{array}$ & \multicolumn{3}{|c|}{$\begin{array}{c}\text { число нажатий на ДП на разных интервалах } \\
\text { сессии } \\
\text { 0-10 мин. | 11-20 мин. |21-30 мин. } \\
\end{array}$} \\
\hline $8-5$ & 246 & $17(6,9 \%)$ & 7 & 3 & 7 \\
\hline $5-8$ & 276 & $13(4,7 \%)$ & 7 & 3 & 3 \\
\hline $4-0$ & 293 & $2(0.7 \%)$ & 2 & 0 & 0 \\
\hline $0-4$ & 320 & $4(1.3 \%)$ & 4 & 0 & 0 \\
\hline $4-0$ & 351 & $2(0,6 \%)$ & 2 & 0 & 0 \\
\hline $6-7$ & 354 & $3(0,8 \%)$ & 3 & 0 & 0 \\
\hline $7-6$ & 266 & $22(8.3 \%)$ & 10 & 4 & 8 \\
\hline $1-2$ & 259 & $8(3.0 \%)$ & 7 & 0 & 1 \\
\hline $2-1$ & 271 & $4(1,5 \%)$ & 3 & 0 & 1 \\
\hline
\end{tabular}

Первая цифра в паре - имя крысы, тестируемой на эмпатию, вторая цифра - имя крысы-жертвы (все крысы самцы). В третьем столбце к числам нажатий добавлены их процентные значения по отношению к общему числу нажатий на обе педали.

Во всех экспериментальных сессиях крысы предпочитали более «экономичный» вариант получения пищи - нажатие на БП, независимо от того, кто был жетрвой (самка или самец, знакомый или чужой), независимо от 
наличия собственного опыта быть жертвой в этом исследовании, независимо от степени голода (в одной из сессий каждая крыса не была голодна, а, кроме того, относительно чаще крысы проверяли эффективность ДП в начале сессии). Для статистически достоверных выводов о некоторых из приведенных выше утверждений, в частности, о независимости от имеющегося опыта быть жертвой, необходимы дополнительные исследования.

Сходство конфигурации медленных потенциалов мозга во всех отведениях, а также в состоянии, когда тестируемая крыса реализует сходное поведение в отсутствие конспецифика или раздражая электрическим током лапы конспецифика, позволяет предположить сходство общемозговой организации поведения в сравниваемых условиях. Вместе с тем, как видно на рис.2, имеются достоверные различия на разных этапах поведения в разных областях коры мозга, которые требуют дополнительного анализа.

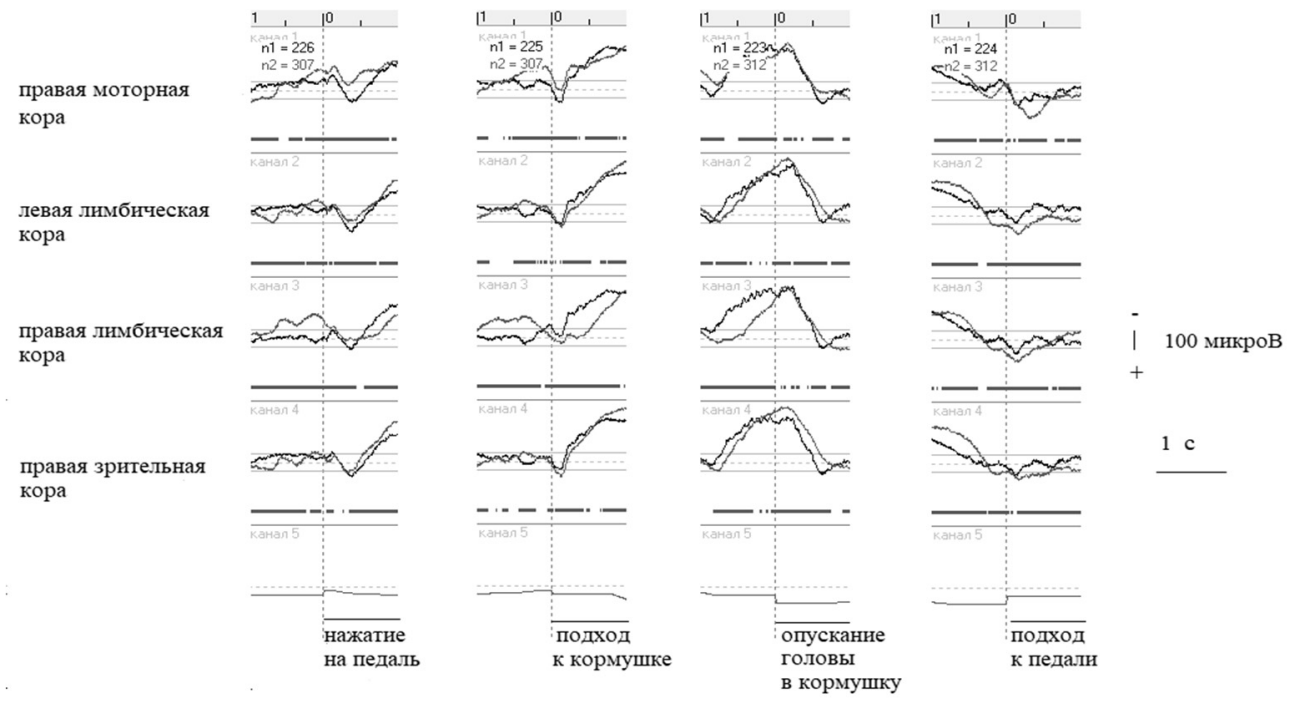

Рисунок 2. Усредненные колебания ЭЭГ при нажатиях на ближнюю педаль (БП) у одной крысы при реализации сходного поведения в отсутствии жертвы в клетке (черный) и в присутствии жертвы (серый), когда нажатие на педаль сопровождается болевым электрокожным раздражением жертвы. Число реализаций в усреднении $n=225$ и $n=307$. Пунктирные линии - синхронизация потенциалов в соответствии с началом актов, указанных на рис..

Обсуждение и выводы. В нашем исследовании ни одна из 8 крыс ни в одной из экспериментальных сессий не “сменила» ближнюю педаль на дальнюю, не уменьшила количество нажатий на ближнюю педаль и не отказалась от поведения при электростимуляции жертвы. В поведении со знакомыми конспецификами, при этом независимо от того, была ли уже крыса 
В положении жертвы или нет, также ни одна из них не проявила эмпатию. В связи с этим, запланированные сопоставления параметров связанных с поведением потенциалов (СПП) в полной мере провести не удалось, однако получены предварительные результаты по сопоставлению параметров СПП у "равнодушных» крыс в одном и том же поведении с электростимуляцией жертвы и в контроле.

Результаты нашего исследования расходятся с результатами, полученными другими исследователями в сходной поведенческой модели [5, 6, 7]. Это может быть связано не только с некоторыми методическими особенностями, в частности, с тем, что в нашем исследовании крысы-жертвы были мягко фриксированы в гамаке и ответ на электрошок выражался в вокализации и подергивании тела, а не заметных прыжках крыс. Другим фактором различий результатов является слабый критерий наличия эмпатии в других работах: несмотря на статистически значимые различия в поведении, число альтруистических актов было сравнительно невелико, что оставляет открытым вопрос, почему в рамках одного эксперимента даже к одному и тому же конспецифику крысы ведут себя по-разному, проявляя эмпатию менее, чем в 50\% процентов случаев.

В проведенном нами исследовании крысы многократно реализовывали одно и то же инструментальное пищедобывательное поведение, поэтому имелась возможность сравнить связанные с поведением потенциалы в индивидуальном поведении и при эмпатии. Поскольку крысы не проявили альтруизм (эмпатию), то и зарегистрировать суммарную электрическую активность мозга в этом поведении было невозможно. Вместе с тем, в связанных с поведением потенциалах мозга испытуемых крыс были найдены различия при реализации инструментального пищедобывательного поведения при электрошоке жертвы и без такового, что означает, что нейрональная организация поведения и актуализация элементов опыта в сравниваемых ситуациях разная.

\section{Литература}

1. Симонов П.В. Условно-рефлекторный подход к анализу внутривидового поведения. Ж. высш.нервн. Деят., 1974, т.24, №3, с.473-478.

2. Швырков В.Б. Введение в объективную психологию: Нейрональные основы психики. Избранные труды. - М., Изд-во «Институт психологии $\mathrm{PAH}$ », 2006.

3. Alexandrov Yu.I., Sozinov A.A., Svarnik O.E., Gorkin A.G., Kuzina E.A., Gavrilov V.V. Neuronal Bases of Systemic Organization of Behavior // Systems Neuroscience, Advances in Neurobiology. A. Cheung-Hoi Yu, L. Li (eds.). 2018 V. 21 P. 1-33.

4. Bekoff M., Pierce J. Wild justice: The moral lives of animals / The University of Chicago Press: Chicago and London, 2009. 
5. Church R.M. Emotional reactions of rats to the pain of others. Comp. Physiol. Psychol., 1959 Apr; 52(2):132-4. https://doi: 10.1037/h0043531.

6. Hernandez-Lallement J., Attah T. A., Soyman E., Pinhal C.M. Gazzola, keysers $C$. Harm to others acts as a negative reinforce in rats. Current Biology, 2020, 30: 1-13. https://doi.org/10/1016/j.cub.2020.01.017

7. Meyza K.Z., Ben-Ami Bartal I., Monfils M.H., Panksepp J.B., Knapska E. The roots of empathy: Through the lens of rodent models. Neuroscience and Biobehavioral Reviews $76 \quad$ (2017) 216-234. http://dx.doi.org/10.1016/j.neubiorev.2016.10.028

8.Rizzolatti G., Fabbri-Destro M., Caurana F., Avanzini P. System neuroscience: past, present, and future. CNS Neurosci Theor. 2018; 1-9. https://doi:10.1111/cnc.12997

9. Waal F.B. Empathetic behavior. Encyclopedia of Animal Behavior, Elsvier Ltd, 2010, 628-632. https://doi.org/10.1016/B978-0-08-045337-8.00105-4.

\section{PSYCHOPHYSIOLOGICAL BASIS OF EMPATHY}

Gavrilov V.V. (Institute of Psychology RAS, Moscow State University of Psychology and Education, Russia)

The ability to empathize is one of the most important in relationships between individuals: it "forces" them to change their behavior, sometimes to their detriment, leads to group cohesion, etc., which makes the study of empathy important and relevant. There are different types of empathy, while only people are usually endowed with true empathy, and ideas about the organization of brain activity and the psychophysiological foundations of empathy are extremely few. Recently, the manifestations of empathy have been associated with the functioning of systems of "mirror neurons", and the phenomenon of empathy itself has been considered on two levels: innate, associated with the presence of" mirror systems", and acquired, associated with"cognitive processing of information". The uncertainty in the definition of empathy, the methodological difficulties and limitations of research on empathy in humans, on the one hand, and the ideas about the structure of individual experience and the organization of brain activity developed in the systemevolutionary approach [2, 3], on the other, allow us to assume that the psychophysiological basis of empathy can be understood as a result of the study of the organization of brain activity in the implementation of "empathic" behavior. The results of a study of empathy and the organization of brain activity in rats in a model of instrumental food-acquisition behavior are reported.

Keywords: empathy, altruism, rats, instrumental behavior. 